\title{
A Review of Practice and Implementation of the Internet of Things (IoT) for Smallholder Agriculture
}

\author{
Anish Paul Antony ${ }^{1, *}$, Kendra Leith ${ }^{1}$, Craig Jolley ${ }^{2,3}$, Jennifer Lu ${ }^{1}$ and Daniel J. Sweeney ${ }^{1}$ (D) \\ 1 D-Lab, Massachusetts Institute of Technology, Cambridge, MA 02139, USA; kleith@mit.edu (K.L.); \\ jennlu@mit.edu (J.L.); dsweeney@mit.edu (D.J.S.) \\ 2 U.S. Agency for International Development, Washington, DC 20004, USA; cjolley@usaid.gov \\ 3 Freedom Consulting Group, Columbia, MD 21046, USA \\ * Correspondence: anishp@mit.edu or iot4ag@mit.edu; Tel.: +1-716-704-9649
}

Received: 1 March 2020; Accepted: 30 April 2020; Published: 6 May 2020

\begin{abstract}
In order to feed a growing global population projected to increase to 9 billion by 2050, food production will need to increase from its current level. The bulk of this growth will need to come from smallholder farmers who rely on generational knowledge in their farming practices and who live in locations where weather patterns and seasons are becoming less predictable due to climate change. The expansion of internet-connected devices is increasing opportunities to apply digital tools and services on smallholder farms, including monitoring soil and plants in horticulture, water quality in aquaculture, and ambient environments in greenhouses. In combination with other food security efforts, internet of things (IoT)-enabled precision smallholder farming has the potential to improve livelihoods and accelerate low- and middle-income countries' journey to self-reliance. Using a combination of interviews, surveys and site visits to gather information, this research presents a review of the current state of the IoT for on-farm measurement, cases of successful IoT implementation in low- and middle-income countries, challenges associated with implementing the IoT on smallholder farms, and recommendations for practitioners.
\end{abstract}

Keywords: internet of things; low-cost sensors; smallholder agriculture; global engineering

\section{Introduction}

In the 1930s, one farmer in the United States could grow enough to feed four people. Today, one farmer can feed 155 people [1]. Approximately 1 billion people worldwide are involved in agriculture, and although the total number of farmers are declining, the demand for agricultural crops is expected to double as the world population reaches 9 billion by 2050 [2]. This will require an increase in agricultural productivity, especially from low- and middle-income countries (LMICs). Recent technological advances have contributed to the rise of precision agriculture, enabling farmers to make better decisions with more information about their soil, water, crop, and local climate $[3,4]$. However, uptake of these advances has been limited to commercial-scale and cash-crop cultivation [1].

There is a growing body of evidence, which indicates that the implementation of precision agriculture tools and practices across different types of farming offers benefits. For example, a digital decision support system (DSS) that utilized crop information provided by growers, in combination with weather data, effectively alerted growers when to apply fungicide to their potatoes, resulting in the effective mitigation of late blight disease and more efficient fungicide use, saving them up to 500 USD per acre cultivated [5-7]. Another DSS platform integrated weather data and electrical capacitance sensors for real-time monitoring of soil water content along with soil water balance and irrigation scheduling models to provide recommendations to durum wheat farmers on timing and intensity of irrigation, resulting in water savings of at least $25 \%$ compared to traditional scheduling 
practices [8]. In another common application, optical sensors attached to fertilizer equipment measure the light reflectance at specific wavebands, which are related to chlorophyll content, an indicator of plant nitrogen $(\mathrm{N})$ content, and fertilizer is applied in that location based on the estimated $\mathrm{N}$ deficiency. Compared to the grower selected constant-rate, sensor-enabled variable-rate fertilization has been shown to increase corn N uptake by more than 20\% [9] and save 10-15 kg N per acre of corn and cotton, especially when soil $\mathrm{N}$ content varies year-to-year [10].

Smallholder farms account for a large share of agricultural production in LMICs and help maintain the genetic diversity of food supply, and mitigate the risks of nutritional deficiencies and ecosystem degradation [11]. However, they face challenges including pressures on farmland from population growth and urbanization, and an inability to rely on generational knowledge and practices due to climate change. Technology advances made through precision agriculture could address some of these challenges [3,12-14]. The internet-of-things (IoT) and the services that it enables has contributed to the rise of precision agriculture, and it is being applied in smallholder agriculture $[4,15,16]$. However, limited research exists that reports outcomes and challenges for implementation of the IoT in smallholder agriculture [3,17]. Thus, this article aims to illustrate the current landscape of the IoT in smallholder farming, summarize specific implementation cases, and describe some of the challenges and recommendations in order to direct this sector.

A typical IoT for agriculture system consists of the following: (i) measurement device, (ii) data transmission, (iii) data storage and analytics, (iv) feedback and implementation, and (v) project structure and support (Figure 1). The device layer consists of a sensor to measure the parameter of interest (e.g., soil moisture) and the electronics necessary to support its functions. Devices are arranged in a topology and connected to a gateway using a communication protocol in the data transmission layer. Broad coverage of cellular networks allows for frequent, and in some cases near real-time, data transmission. Individual or aggregated measurements are received by a server where they can be queried, cleaned, and analyzed. Relevant insights are fed back to an end-user or other IoT devices to inform decisions and prompt actions. A vast catalog of existing products and services that are tailored for specific applications make each of these operations increasingly easier and provide a lower cost to implement. More detailed introductions to IoT architecture design and theory can be found in $[18,19]$. This review primarily focuses on categories (i) and (ii), accompanied by discussion of the implications on (v).

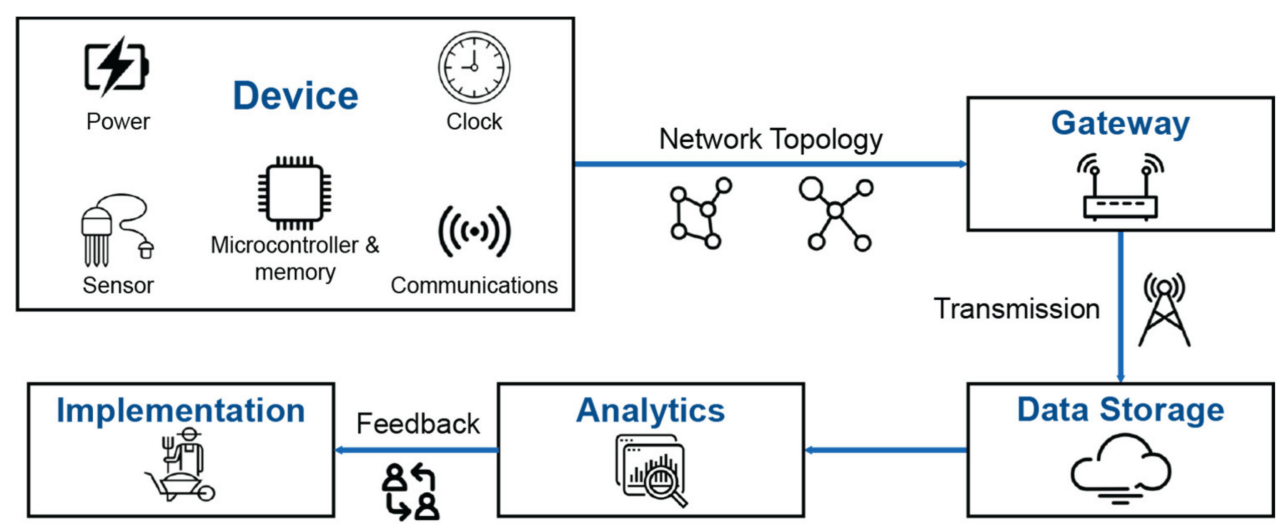

Figure 1. Internet of things (IoT) for agriculture architecture.

An important enabler for IoT services in LMICs (and a sub-set of LMICs-global food security strategy (GFSS) countries [20]) is reliable cellular infrastructure [21]. Country level data from the World Bank suggests that the GFSS country set average for cellular connections and smartphone penetration is on par with India, a common benchmark for digital services among developing countries (Figure 2). However, the linkage has not yet been made to the agricultural sector. Internet usage in GFSS countries ranges from $10 \%-50 \%$ of the population and correlates inversely with the population 
employed in agriculture (Figure 3a). Where access to internet falls short, digital services often benefit from cellular connectivity. However, while agricultural productivity has increased in most GFSS countries, those gains show no correlation with mobile phone penetration (Figure 3b). For example, a recent study has shown that mobile phone ownership in farming households is nearly universal; however, fewer than $25 \%$ use a phone to access information about agriculture and livestock, or for buying and selling products [22]. These data, and more from the GFSS agriculture dataset, can be accessed in the Supplementary Materials.

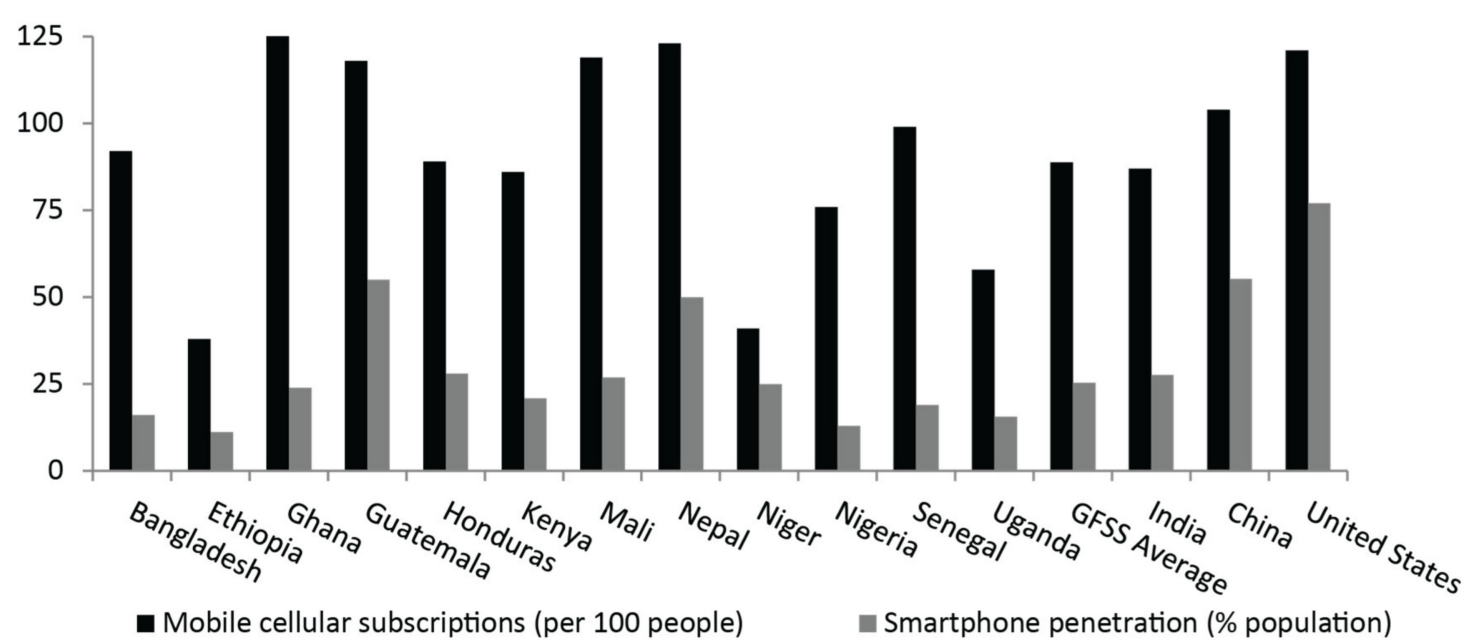

Figure 2. Mobile phone subscriptions and smartphone penetration across the global food security strategy (GFSS) country set, India, China, and the United States [23,24].
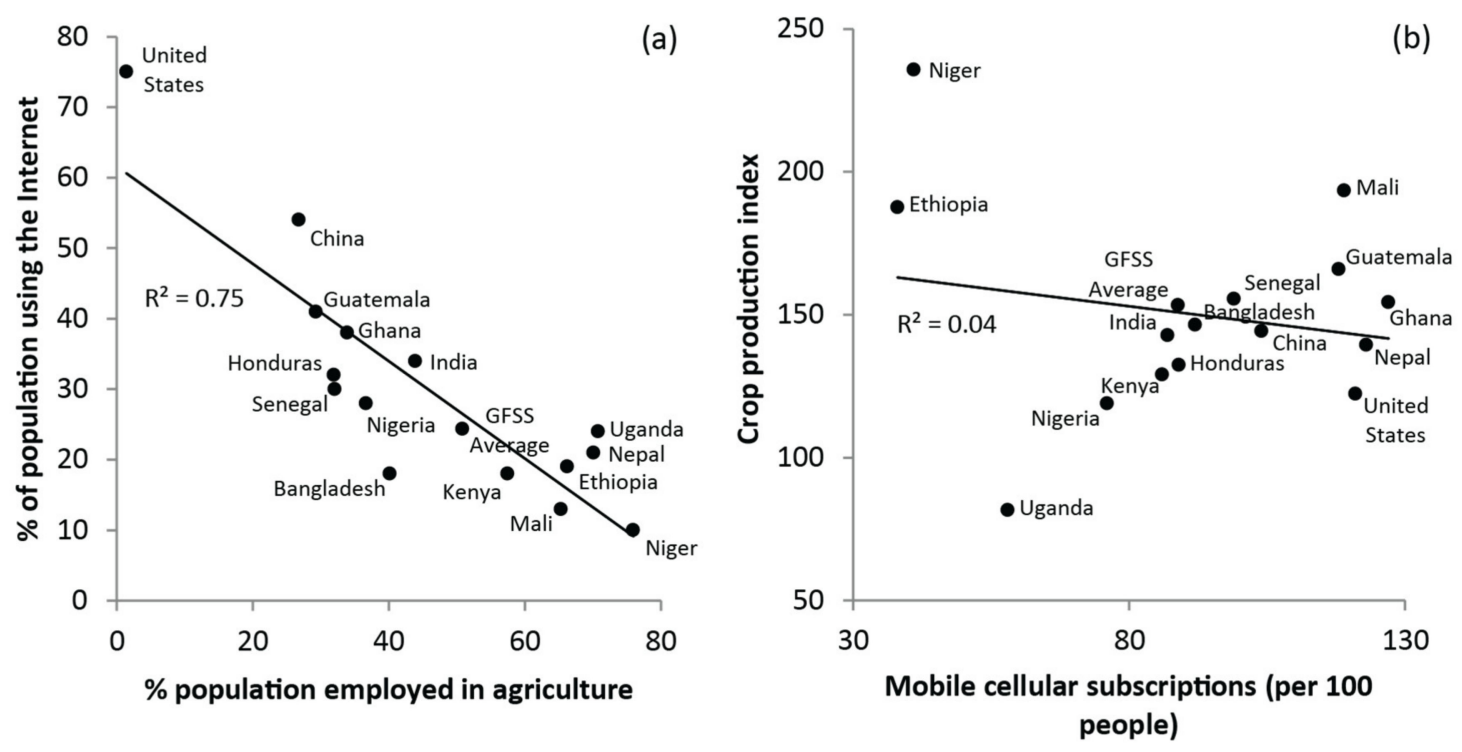

Figure 3. (a) Agriculture and internet usage across the GFSS country set, India, China, and the United States [23] (b) Crop productivity and mobile connectivity [23]. Crop production index (CPI) shows agricultural production for each year relative to the base period 2004-2006 (CPI = 100). It includes all crops except fodder crops.

\section{Approach}

A mixed method approach consisting of a combination of literature reviews, expert interviews, web-based surveys, and site visits were used to carry out this research [25-27]. The literature review included a review of 87 relevant publications, which are catalogued in an open online repository [25]. This review provided an overview of sensors and IoT for agriculture globally. Next, 25 interviews with 
relevant experts worldwide were conducted. These expert interviews were used to identify the gaps in understanding the value of the IoT to smallholder farmers and potential directions for technology development in this sector. Seventy web-based surveys were then distributed to stakeholders in the IoT and agricultural technology communities from which we received 37 responses; these web-based surveys served to not only triangulate the expert interview data, but also to provide use case profiles for our site visits. Finally, five site visits and discussions with farmers at IoT implementation sites in India and Kenya were conducted. The site visits were used to validate findings from the literature review, expert interviews, and web-based surveys. Two countries were selected for the site visits; (i) India, which was selected because of the large number of agricultural technologies being piloted and implemented there on smallholder farms, and (ii) Kenya, where we conducted a majority of our site visits. Among the different GFSS countries, Kenya had the most active IoT for agriculture projects, and this influenced our selection.

\section{Results and Discussion}

\subsection{Current State of IoT for Agriculture}

For this overview of IoT for agriculture, sensor and communication technology applications are classified into five categories of (a) climate, (b) livestock, (c) plant, (d) soil, and (e) water. Within each category, there are many common, measurable parameters that can influence the performance of the agricultural system (Figure 4). This categorization focuses on "ground-based" measurements, while other methods exist including aerial- and space-based earth observation or remote sensing, for example in $[26,28]$. In some cases, remote sensing and ground-based measurements are combined to provide temporally (ground-based sensors) and spatially (remote sensing) dense crop measurements [29].

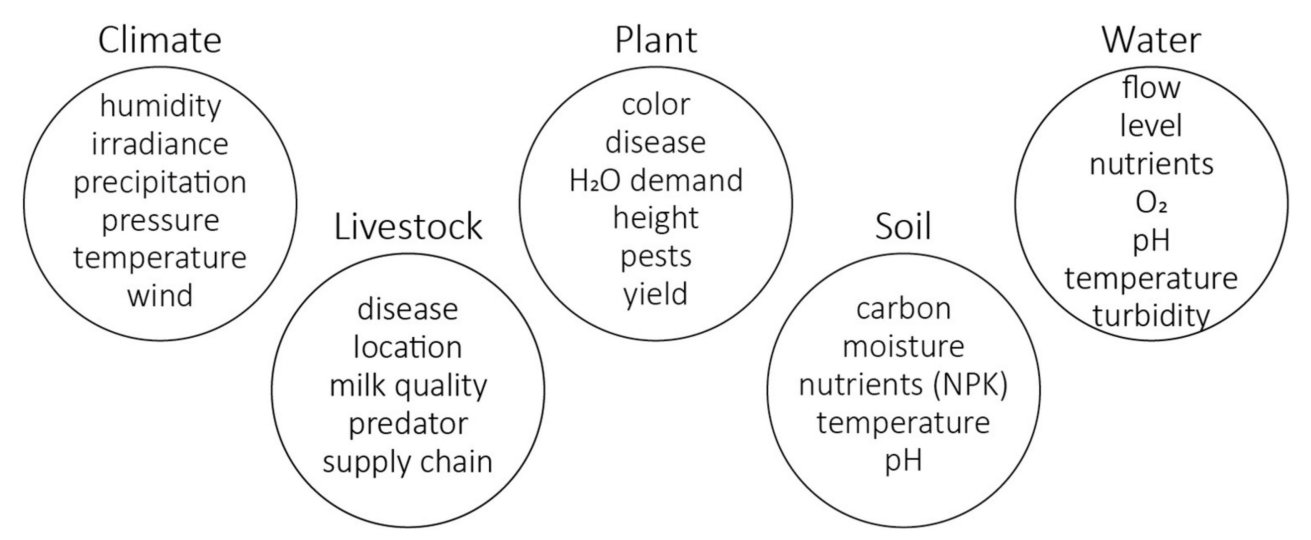

Figure 4. Measurement categories and related measurable parameters.

Table 1 summarizes common electronic sensors, their applications in agriculture, and articles that describe those in more detail. Wherever available, articles that report on applications in LMICs are included, although relevant precision agriculture research from across the globe is also included. Some parameters can use different technologies to estimate the same output. Methods for measuring basic agricultural parameters, including soil and atmospheric conditions, are well-established, and commercial products are available for IoT applications. New applications for optical sensors, in particular, are evolving as the cost of semiconductor technology and data storage and transmission decreases. A particular challenge with using low-cost sensors in agriculture is the need to calibrate the sensor for the specific implementation conditions. For applications where artificial intelligence (AI) is applied to classify events based on measurement patterns, complex training datasets are necessary to teach the AI algorithm. 
Table 1. Sensor types and corresponding agricultural parameters.

\begin{tabular}{|c|c|}
\hline Sensor Type & Agricultural Parameter \\
\hline Electrical capacitance & Soil moisture [30-35], ambient humidity $[36,37]$ \\
\hline Electrical conductivity & Soil moisture [34,38-40], soil and water $\mathrm{pH}[41]$, ambient humidity $[34,42]$ \\
\hline Load cell & Weight of harvested crops $[43,44]$, crop waste [45] \\
\hline Electrochemical & $\begin{array}{l}\text { Ethylene concentration in crop storage [46], greenhouse } \mathrm{CO}_{2} \text { concentration } \\
\qquad[47,48] \text {, beehive monitoring [49] }\end{array}$ \\
\hline Optical & $\begin{array}{c}\text { Crop height measurement [50,51], livestock and predator monitoring [52], } \\
\text { volume of harvested grain [53], plant mapping [54], NDVI [55], soil } \\
\text { composition [56-58], N content [9,10,59], solar irradiance [60], plant disease } \\
\text { detection [61], crop waste [45] }\end{array}$ \\
\hline Thermocouple, thermistor & $\begin{array}{c}\text { Seed and crop storage [62], greenhouse monitoring }[34,48,63] \text {, soil } \\
\text { temperature }[34,64] \text {, water temperature }[65]\end{array}$ \\
\hline Pressure and flow rate & Irrigation water flow [66], handpump usage [67] \\
\hline Acoustic & Animal detection $[68,69]$, water level [70], grain silo level [3] \\
\hline Accelerometer & Livestock monitoring [71,72], crop transport [73], handpump usage [67] \\
\hline Magnetic flux & Electrical current and power consumption [74] \\
\hline RFID & Livestock and poultry tracking $[75,76]$, supply chain tracking, asset tracking \\
\hline GPS & $\begin{array}{l}\text { e-Extension [77], equipment navigation, livestock tracking [76,78], wireless } \\
\text { fencing, asset tracking [79] }\end{array}$ \\
\hline
\end{tabular}

In addition to the measurement device, careful consideration should be given to the path and process by which measurements are transformed into insights. Data transmission can represent a major challenge in smallholder agriculture applications. Edge computing is becoming more common in commercial IoT products, in which onboard device memory and processing capacity is utilized to carry out some data reduction and analysis [80]. However, for insights that require a large quantity of measurements or computational power, transmitting data to the cloud for computing will be required. Table 2 summarizes common IoT data transmission protocols and their associated advantages and disadvantages.

The IoT for smallholder agriculture represents a challenge for data transmission due to remote locations, with devices distributed over large areas or multiple farms that have potentially limited access to electricity and cellular networks. Therefore, the range, data rate, and power consumption are important design considerations and are compared for the common communication protocols.

In Figure 5, communication protocols are grouped based on data rate and range of transmission, which is divided into "Long range", including low-power wide area network (LPWAN), which includes LoRa and SigFox, "Short range", including Bluetooth Low Energy (BLE), Zigbee, and Z-Wave, and cellular communication including GSM 2G, 3G, 4G, and 5G. With respect to power consumption, solutions that are tailored to IoT applications offer superior performance to more general protocols (Figure 6). While the range and power consumption of protocols like LoRa and SigFox are well suited for IoT applications, their device compatibility is more limited compared to generic wireless protocols like Bluetooth and WiFi. Additionally, cellular and satellite communication offer the advantage of providing a direct link to a web server instead of passing through an intermediate gateway. 
Table 2. IoT data transmission protocols.

\begin{tabular}{|c|c|c|c|}
\hline Protocol & Description & Advantages & Disadvantages \\
\hline Zigbee & $\begin{array}{l}\text { IEEE 802.15.4-based } \\
\text { specification using mesh } \\
\text { network topology and suitable } \\
\text { for short- to medium-range }\end{array}$ & $\begin{array}{l}\text { Long battery life (node sleep } \\
\text { mode) } \\
>65,000 \text { nodes in a mesh } \\
\text { network } \\
\text { License-free frequency band }\end{array}$ & $\begin{array}{l}\text { Short range }(10-100 \mathrm{~m}) \\
\text { Incompatibility with other } \\
\text { protocols } \\
\text { Signal interference in } \\
2.4 \mathrm{GHz} \text { band }\end{array}$ \\
\hline Z-Wave & $\begin{array}{l}\text { Mesh network protocol that } \\
\text { uses low-energy radio waves } \\
\text { and proprietary radio system }\end{array}$ & $\begin{array}{c}\text { Devices are interoperable } \\
\text { Suitable for low-power } \\
\text { devices }\end{array}$ & $\begin{array}{l}\text { Max } 232 \text { nodes in a mesh } \\
\text { network } \\
\text { Not suitable for high-power } \\
\text { devices }\end{array}$ \\
\hline LoRa (Long Range) & $\begin{array}{l}\text { Long-range, low-power, and } \\
\text { low-bitrate protocol that uses } \\
\text { star topology and unlicensed } \\
\text { ISM frequency bands }\end{array}$ & $\begin{array}{c}\text { Long range }(10 \mathrm{~km}) \\
\text { Low power consumption }\end{array}$ & $\begin{array}{c}\text { Actual line-of-sight range of } \\
\sim 2 \mathrm{~km} \\
\text { Large bandwidth for data } \\
\text { transmission }\end{array}$ \\
\hline $\begin{array}{l}\text { Bluetooth Low Energy } \\
\text { (BLE) }\end{array}$ & $\begin{array}{l}\text { Wireless personal area } \\
\text { network with low power } \\
\text { consumption and cost }\end{array}$ & $\begin{array}{l}\text { Broad device support } \\
\text { License-free } 2.4 \mathrm{GHz} \text { band } \\
\text { Frequency-hopping reduces } \\
\text { signal interference }\end{array}$ & $\begin{array}{l}\text { Low bandwidth } \\
\text { Short range }(<100 \mathrm{~m})\end{array}$ \\
\hline $\begin{array}{l}\text { SigFox low-power wide } \\
\text { area network (LPWAN) }\end{array}$ & $\begin{array}{l}\text { Proprietary service tailored to } \\
\text { IoT networks in a star topology } \\
\text { operating on unlicensed ISM } \\
\text { frequency band }\end{array}$ & $\begin{array}{l}\text { Low power consumption } \\
\text { Low-cost because the } \\
\text { network and computing } \\
\text { complexity is managed in } \\
\text { the cloud }\end{array}$ & $\begin{array}{l}\text { Not supported in all } \\
\text { countries } \\
\text { Susceptible to signal } \\
\text { interference in some } \\
\text { countries }\end{array}$ \\
\hline
\end{tabular}

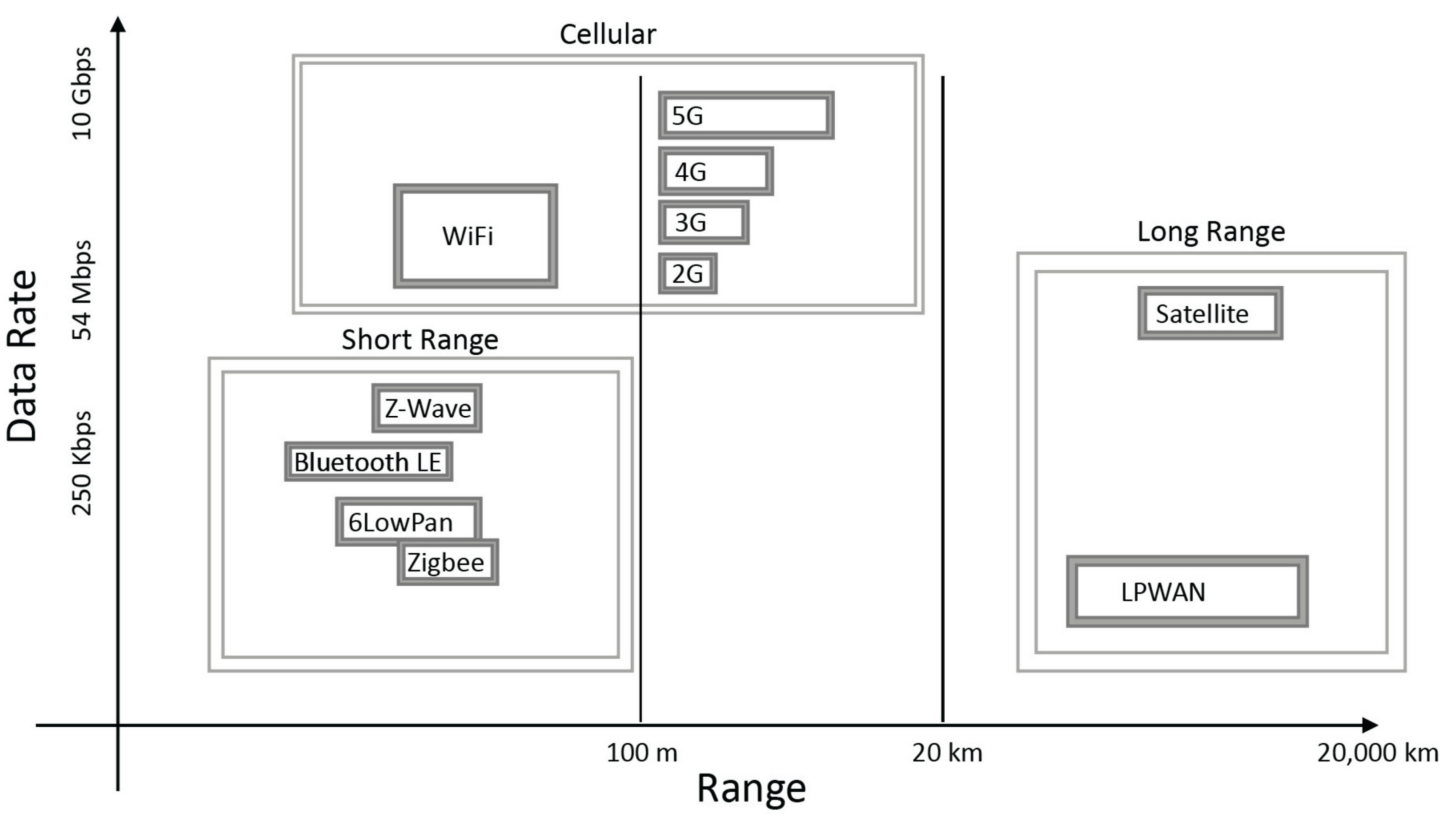

Figure 5. Range vs. data rate for common communication protocols [81]. 


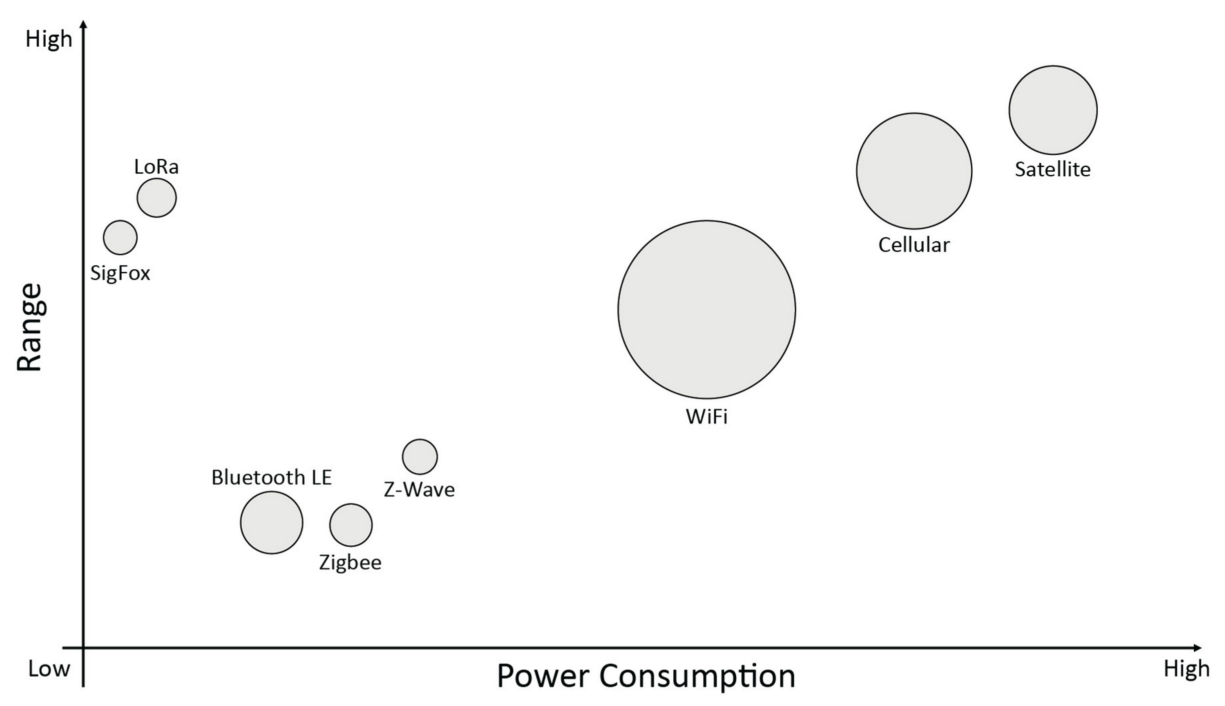

Figure 6. Power consumption vs. range for common communication protocols [81,82]. Bubble size is proportional to data rate.

Even though many organizations in LMICs have developed IoT systems for agriculture, few studies have reported on the implementation in a smallholder context and associated outcomes. Research in Embu County, Kenya tested different proximal soil sensors to estimate soil properties and composition on smallholder plots and provided management recommendations to farmers [57]. The measurements showed considerable variation, both within plots and regionally, indicating a need for management recommendations based on both local measurements and regional soil maps. Another application implemented a tracing system for smallholders who raised live poultry that were traded in Vietnam to prevent the spread of avian influenza [75]. Low-cost radio-frequency identification (RFID) tags on transport cages and electronic tag readers at markets tracked birds from farm-to-market, revealing that birds passed through up to six intermediate traders, creating a high risk of virus transmission. Many commercial entities serving smallholder farmers use the IoT to track assets and interface digitally with customers; for example, tractors and implements for hire by Hello Tractor in West Africa and EM3 AgriServices in India [83], and irrigation equipment by Agriworks, Futurepump, and SunCulture in East Africa [84]. Enrollment in these services is enabling more productive growing; however, low digital literacy is a barrier that requires a mix of traditional and technology-enabled engagement with farmers. A notable case is the use of sensors to monitor borehole pump reliability for potable and irrigation water supply in East Africa, which is discussed later in this article.

\subsection{Implementation Cases}

In addition to reviewing the literature and interviewing experts, we found it useful to study on-the-ground implementations of the IoT for smallholder agriculture. In particular, this research aimed to understand what helps to create an enabling environment at the country level, and the keys to success and the risks associated with active IoT in smallholder agriculture projects in India and Kenya.

India is home to over 130 million smallholder farms [85] and is a common testbed and incubator for digital services for farmers. Site visits and discussions in India focused on identifying the factors that enable innovations in the agricultural sector in order to promote those in GFSS countries. The following is a summary of those factors.

- Mobile network connectivity and cost: Relatively cheap monthly mobile data plans of 0.21 USD/GB $[38,39]$ have helped IoT companies explore opportunities to work with sensors using cellular services for data transmission.

- Market opportunity: The large population size and density, and increasing incomes of the Indian middle class, make India a lucrative market for IoT providers [41]. 
- Policies to support farmers: Agriculture accounts for 17.32\% of India's GDP and employs over $50 \%$ of the population, and some state governments are providing subsidies for new farm equipment that could be leveraged towards precision agriculture purchases [40].

- Academic institutions: Some of the highest ranking academic institutions in India are performing research that benefits Indian farmers and are raising the awareness of farming challenges to students through hackathons.

Kenya represents a very different landscape compared to India. The population and total number of farm holdings are vastly smaller, and many of the enabling factors discussed above are yet to emerge. However, Kenya was selected because, among the different GFSS countries, the authors' investigations and discussions revealed several active IoT for agriculture cases across different applications and locations in Kenya. These cases are summarized in this section along with some of the keys to the success and the associated risks with project sustainability.

As part of the Kenya Resilient Arid Lands Partnership for Integrated Development (RAPID) project to manage the recently discovered Lodwar Basin Aquifer in northern Kenya, electrical current sensors were installed on solar-electric borehole pumps to monitor "water system functionality, the approximate number of pumping hours and volume extracted per day, and the last report date for the sensor" [86]. Data from the current sensors are transmitted via cellular or satellite network to a web server and dashboard where county government staff can monitor borehole use. While the pumped water serves a variety of community needs, some is used for irrigating small farm plots on municipal land that would otherwise be infertile (Figure 7). One of the keys to the success of this IoT implementation was the clear value and utility to the government officials responsible for the pumps, who indicated that access to the dashboard significantly reduced maintenance costs and pump downtime. The Kenya RAPID project also benefits from having a large, distributed, and well-coordinated team where each organization plays a clear role, including the supplier of the IoT technology. The sensor measurements have revealed detailed pump usage patterns in relation to rainfall [74], and this, coupled with a machine learning algorithm to predict failures and reduce detection time, has resulted in an increase in system-wide pump uptime from $70 \%$ to $>99 \%$ [87]. A risk for the project is the current reliance on grant funding, although the IoT component has now been incorporated into the county government budget.

\section{Borehole pump monitoring for small plot community farming in Turkana}
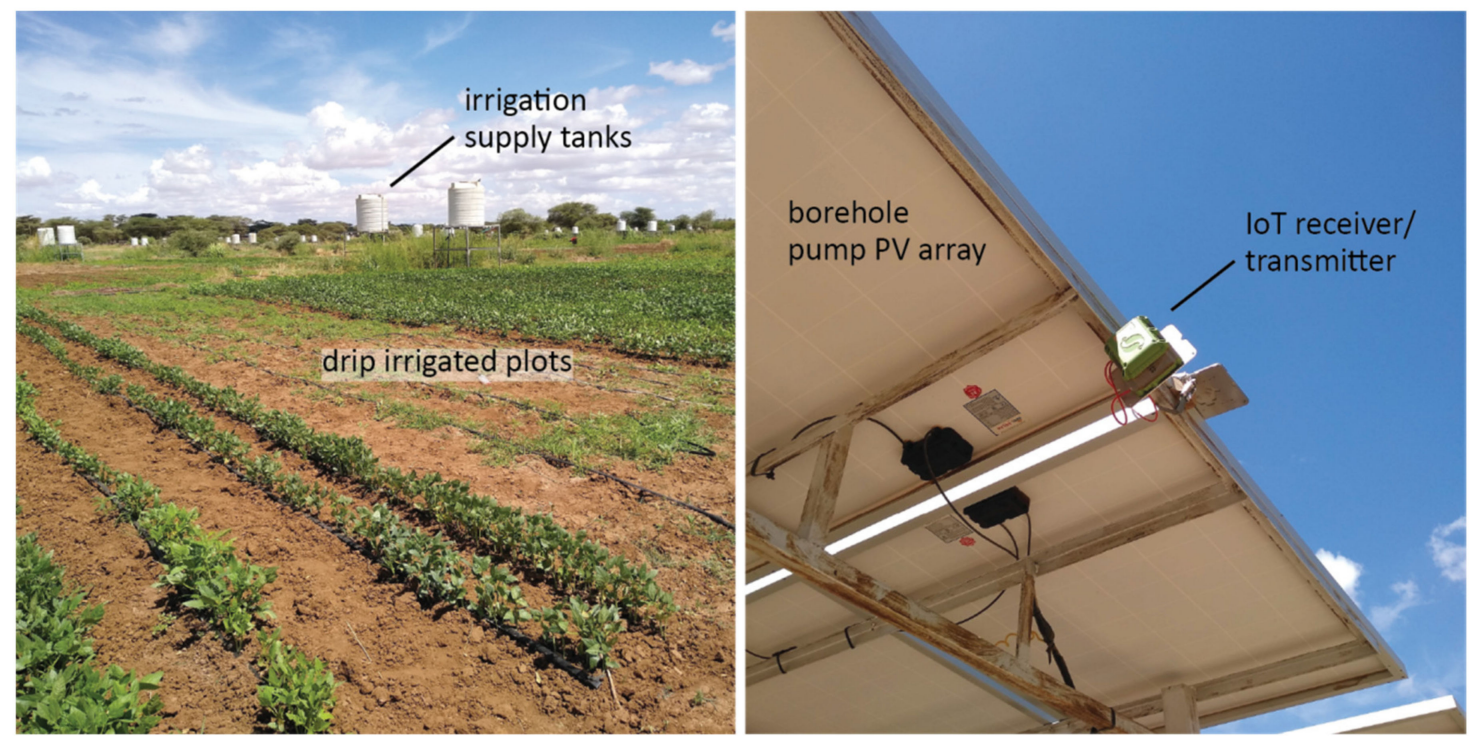

Figure 7. Drip-irrigated vegetable cultivation at Napuu: Drip Irrigation Scheme in Lodwar, Kenya (left), and a SweetSense gateway mounted on solar PV panels that transmits solar irrigation pump usage data to an online server via cellular or satellite data (right). 
The IoT solution for the aquaponics system at Kikaboni Farm was developed by Upande, and it monitors water conditions (temperature and $\mathrm{pH}$ ) in the fish tanks and environmental conditions (ambient temperature and relative humidity) in the hydroponic vegetable growing area (Figure 8). The sensors are battery-powered, charged by 3-10 W solar PV panels, and transmit measurements over a LoRa network to a gateway with a mobile data connection. Data are stored and processed on Upande servers and regularly fed back to the farm's horticulture manager who can perform necessary adjustments. For example, the cover material for the vegetable structure was changed after measurements showed that temperatures were far above the recommended growing temperatures for leafy green vegetables (Figure 8). One of the keys to success for this application is the ability of the horticulture manager to interpret the data, which has allowed them to make significant improvements to their product yield and quality. Kikaboni Farm has also collaborated on product development by providing a testbed for improvements to Upande Vipimo IoT products.

A risk for this project is the reliance on the expertise and willingness of the horticulture manager.

Water and greenhouse monitoring for aquaponics in Olooloitikosh

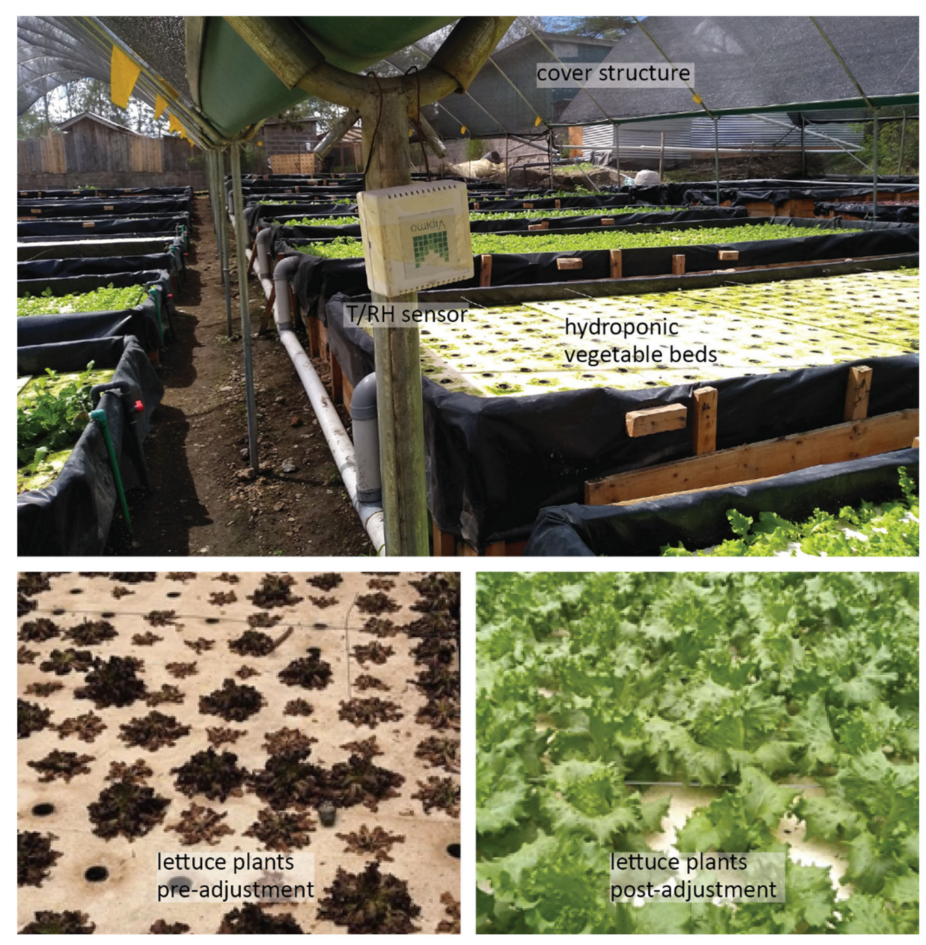

Figure 8. (top) Upande Vipimo temperature and relative humidity sensor in the aquaponics greenhouse at Kikaboni Farm. (bottom) Lettuce plants growing in the aquaponics beds before (left) and after (right) improvements to the growing environment.

With little vegetation in the Mara River watershed, rainy season precipitation causes rapid river level rise and destructive flooding (Figure 9). The IoT solution developed by Upande consists of solar-battery powered sound navigation and ranging (SONAR) level sensors at several points along the river, connected by LoRa to several grid-connected gateways with cellular access. In the event that the level sensors detect a rapid river level rise, an SMS-based system is activated, which alerts downstream farmers to pump water out of the river in order to open capacity to receive the upstream surge. One of the keys to the success of this system is the dedication of volunteers to coordinate activities, maintain the IoT system, and host workshops to engage the local communities. Some of the risks to the sustainability of this project are a lack of financial support, the rugged and remote conditions that the IoT must survive in, and the inconsistent support from the county government to allow the system to operate. 

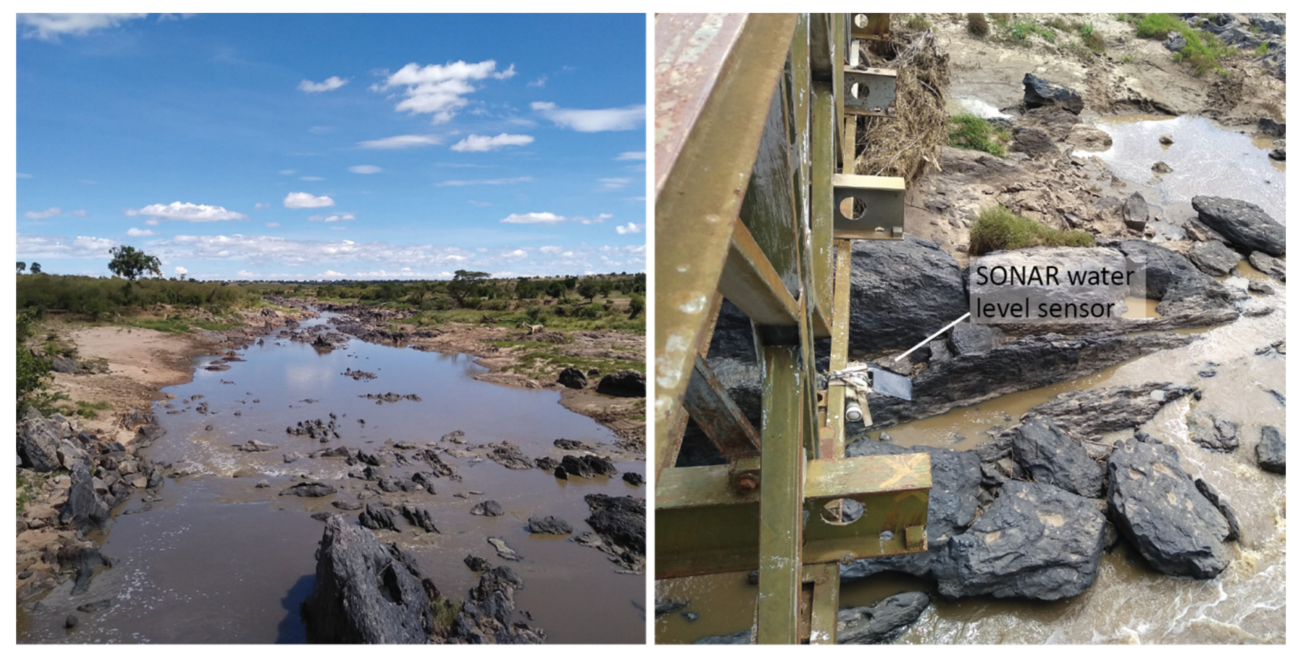

Figure 9. The Mara River in the Maasai Mara National Reserve (left), and a SONAR level sensor installed on a bridge over the Mara River (right).

Greenhouses offer the opportunity for small farmers to grow high-value vegetables throughout the year in a controlled environment. However, uncontrolled greenhouse conditions can be harsh and damaging to plants. Researchers at the Dedan Kimathi University of Technology developed an IoT temperature, relative humidity, and soil moisture sensor coupled to an internet-connected gateway to assist farmers on their research farm (Figure 10) [34]. In this case, the system relies on the expertise of the farmers to interpret data and make the proper adjustments to the greenhouse. The farmers showed a high level of satisfaction with the system and reported that it had greatly improved productivity of tomatoes in their greenhouses. A key to the success of this project is the close connection and proximity between the IoT developers and the farmers, and the ability of the farmers to interpret the sensor measurements. This project is also equipping engineering students with the skills and experience needed to provide commercial IoT for agriculture solutions in Kenya [88]. A potential risk to the sustainability of this project is that steady funding is needed to build a pipeline of work given the expertise, location, and access to research agriculture facilities.

Greenhouse monitoring in Nyeri

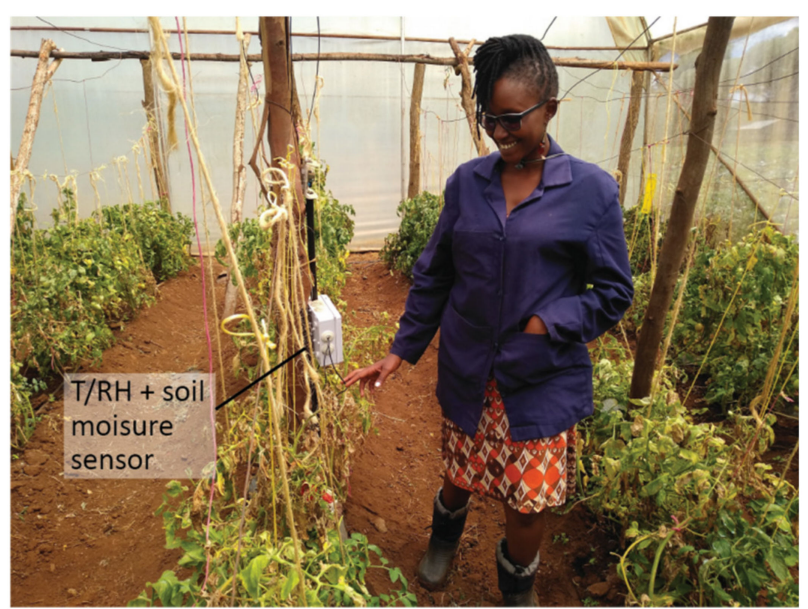

Figure 10. Greenhouse Supervisor inspecting tomatoes and a temperature, humidity, and soil moisture device in a greenhouse at the Dedan Kimathi University of Technology research farm. 
To supplement the limited information available to smallholder farmers, Arable has developed a multi-parameter IoT device with a suite of sensors for measurements including ambient temperature, humidity, precipitation, Normalized Difference Vegetation Index (NDVI), and photosynthetic active radiation (Figure 11) [22,60]. During current pilots in central Kenya, the devices are installed on smallholder farms and data is transmitted through cellular network to cloud servers where it is stored and analyzed. Reduced data is fed back to Kenyan partner researchers and agriculture extension agents who offer advice to area farmers. Agriculture extension agents reported that the local-scale information is a valuable supplement to regional forecasts provided by the Kenyan government and help them to provide better advice to farmers. A risk to this project is the challenge of determining an economical pathway to sustain and expand the IoT technology and staff in the ecosystem.

\section{Monitoring smallholder maize plots in Nanyuki}

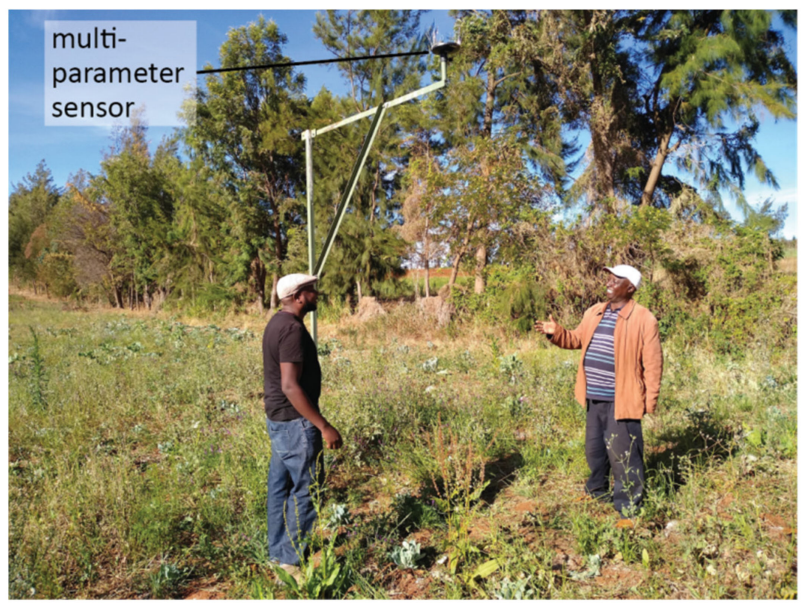

Figure 11. A researcher and farmer discussing a multi-parameter sensor installed on a farm in Nanyuki.

\subsection{Discussion of Challenges and Recommendations}

Based on our literature review, expert interviews, surveys, and site visits, the team has synthesized a list of the challenges in IoT for smallholder agriculture in GFSS countries (summarized in Figure 12), and proposed recommendations for some of the relevant players involved. The following section is a summary of challenges grouped into five categories, which correspond to the IoT architecture in Figure 1: (i) measurement device, (ii) data transmission, (iii) data storage and analytics, (iv) feedback and implementation, and (v) project structure and support. A detailed discussion of the challenges, opportunities, and recommendations for the IoT for smallholder agriculture can be found in the full project report [25]. We believe that this section will be appealing to audiences beyond the academic and research community, and specific recommendations are segmented towards Technologists, Project managers, and Funders.
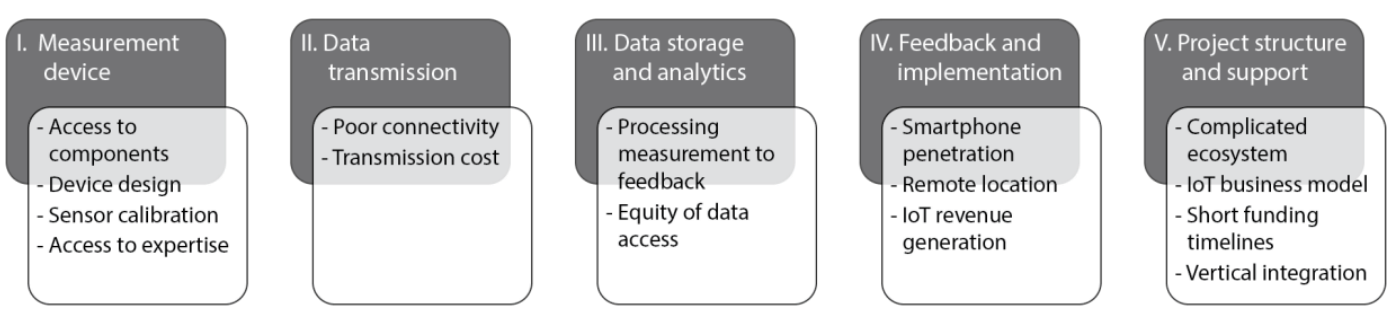

Figure 12. Challenges in IoT for smallholder agriculture. 


\subsubsection{Measurement Device Challenges}

Access to components: Off-the-shelf IoT products are often not available, suitable, or affordable for commercial technologies in developing countries. Therefore, custom made solutions are designed in-house or by local IoT companies. During our site visit in Kenya, a number of IoT implementation teams that we spoke to indicated that procuring electronic and hardware components during the product development phase often delayed the project and increased costs.

Technologists: A good starting point for prototype circuit components is the local electronics and scrap market (e.g., CBD in Nairobi, Kisenyi in Kampala, Suame Magazine in Kumasi). These markets usually stock basic circuit and prototyping components that can be used as a "good enough" solution to reach a proof-of-concept prototype.

Device design: Smallholder farms are often in rugged and remote locations and require special consideration when designing a connected, electronic device for long-term monitoring.

Technologists: As soon as possible in the design process, test your device at a pilot site that is representative of the actual implementation site.

Project managers: Involve the farmers, agriculture extension agents, and farmer co-operatives in the product design phase to help your team identify non-obvious challenges and improve the likelihood that farmers will accept the idea.

Sensor calibration: Correlating the raw sensor measurements to actual physical values requires performing controlled calibration tests that can be expensive and time consuming.

Technologists: Aim to eventually provide calibration documentation for your product so that it can be benchmarked against other products and measurement methods. Perform some simple tests to check factory-calibrated sensors in conditions as close to the implementation conditions as possible in case there is a need to apply a correction factor.

Access to expertise: Many teams we visited mentioned a lack of access to expertise and resources for technical and business challenges. For example, several engineers reported spending significant amounts of time combing through websites to find technical solutions during their product development.

Technologists: Participate in online communities focused on IoT for agriculture hardware, especially for idea exchange, technical support, and recruiting. For example, we found the Gathering of Open Ag Tech to be a good example of such a resource in the agriculture sector (forum.goatech.org).

\subsubsection{Data Transmission Challenges:}

Poor connectivity: Due to the remote location of some farming communities, poor mobile network connectivity and reliability is a common challenge.

Technologists: As a last resort, data can be collected manually, i.e., from a central hub connected to individual devices by a local wireless network.

Project managers: Check mobile network coverage in your implementation area using GSMA maps and cross-check with non-industry sources, for example, a compilation of user contributed Nperf data.

Transmission cost: While data costs have decreased significantly, the recurring cost of providing IoT services was frequently identified as a challenge for commercial applications.

Technologists: For some applications, satellite and LPWAN-based service providers are increasingly cost-competitive with conventional mobile data.

\subsubsection{Data Storage and Analytics}

Measurement to feedback: Raw sensor measurements can be difficult to reduce into actionable recommendations for farmers.

Project managers: While measurements are relatively easy to display on a dashboard, correlating them with crop growth and other effects requires input from a topical expert. Accessing the right 
expertise can be a challenge in itself, but resources at universities and agricultural extension agencies can often give some direction.

Technologists: Take a human centered approach by having farmers and agriculture experts from the area provide input on (a) what kind of recommendations would be useful and actionable and (b) the best means for the farmer to receive the recommendation.

Equity of access: The ownership of data collected is often overlooked in IoT projects and can lead to disagreements among stakeholders.

Project managers: Negotiate data access with project partners and funders. While it is important to maintain community access to data, service providers and funders may have requirements for data access.

Funders: Communicate early with the project implementers and have clear guidelines on data access, privacy, ownership, and sharing mechanisms of the data with the community.

\subsubsection{Feedback and Implementation}

Smartphone penetration: Many agriculture advisory mobile apps are designed for use on a smartphones; however, smartphone penetration is low among rural populations in GFSS countries $[89,90]$.

Project managers: Make sure the output is reaching the intended audience in a format that is accessible to them. If smartphone penetration is low, then using another medium such as radio, television, local print media, or extension agents can be appropriate to provide recommendations to farming communities [17]. Early discussions with farmers, farmer co-operatives, and agriculture extension agents could help to make sure that the output is reaching the audience through the right communication channel.

Remote location: Many smallholder farms are in remote, difficult-to-access locations, which can add significant cost to IoT services if technicians need to regularly visit farms.

Technologists: Incorporate onboard diagnostics for your device (e.g., battery voltage, microcontroller temperature, accelerometer) in order to minimize maintenance visits.

Project managers: Identify a local farmer or extension agent who can assist with basic sensor maintenance and troubleshooting, for example, the horticulture manager at Kikaboni Farm described in Section 3.2.

IoT revenue generation: Identifying the best customer for the information collected is important. In many cases, there is an opportunity to provide a service along with the hardware, which can provide recurring revenue.

Project managers: Many IoT for agriculture projects are initially grant funded, and determining approaches to monetize data and analytics services will help ensure project sustainability. Consider this aspect when agreeing on the terms of the funding.

\subsubsection{Project Structure and Support}

Complicated ecosystem: Successfully implementing an agriculture-IoT project involves coordination of a large, and sometimes complicated, ecosystem of actors over a long timescale.

Project managers: Try to organize a team of collaborators that includes data scientists, sensor experts, and agriculture experts so that each is contributing to solving a specific part of the problem in which he/she is an expert.

IoT business model: Most people we connected with during this project agreed that data from on-farm sensors is valuable. However, identifying a specific customer, or buyer, of the device or service is less straightforward, especially when the beneficiary is unlikely to have the means to afford the technology.

Project managers: Identifying and understanding whom the end customer is and who will be paying for the data is important. A good example is the Kenya RAPID project, described in Section 3.2, in which the county government includes the IoT services in their annual budget. 
Short funding timelines: Two- and three-year grants from donor agencies are short timelines; when it comes to farming seasons, this is a relatively short time period because you get data from only one or two cropping cycles, so collecting quality data and making actionable recommendations is a challenge.

Funders: Increase funding timelines to five to seven years to allow for data collection over multiple cropping periods. A larger dataset also enables better pattern recognition and predictive analytics, leading to suitable actionable recommendations.

Vertical integration: Many organizations are providing an end-to-end solution in which a single organization takes on the responsibility of farmer recruitment, IoT technology development, implementation, data analysis and recommendations, and monitoring and evaluation.

Project managers: Some of the key stakeholders the team spoke with indicated that, while they were experts in a few aspects of the IoT and agriculture, trying to work on the entire end-to-end process of an agriculture IoT ecosystem was stretching them thin; thus, incorporating a horizontal structure in which each organization offers specific expertise to solve the overall problem in a piecemeal fashion is favorable for project success.

Funders: Funding agencies can play a facilitation role to connect diverse groups with specific expertise to solve the overall problem. Organizations forming new partnerships could particularly benefit from guidance in negotiating agreements and contracts.

\section{Conclusions}

This review presents a perspective of the current state of the IoT in smallholder agriculture, including summaries of state-of-the-art sensor and communication technologies and real examples of IoT implementation on farms in Kenya, and the challenges and recommendations associated with the implementation of IoT on smallholder farms in LMICs. The barriers and challenges are largely known and surmountable, and viable implementation of the IoT is already occurring. Currently, applications for scenarios with easily detectable and actionable parameters offer more immediate promise and likelihood of uptake than those implementing measurements that are more difficult to interpret. Additionally, targeting measurements that address a significant pain point (e.g., water supply reliability) can ensure buy-in from and value to the communities involved. Major evolving challenges due to climate change will motivate implementation of the IoT to improve resilience and secure safety nets for global food supply. Greater resilience and agricultural productivity have the potential to strengthen rural economies and help developing countries along their journey to self-reliance. The IoT for agriculture objective remains: To gather sufficient quantities of data of the right type, from the right location, at a low cost, and with sufficiently well-informed analysis and understanding for farmers to take action.

Supplementary Materials: The following are available online at http:/www.mdpi.com/2071-1050/12/9/3750/s1.

Author Contributions: Conceptualization, A.P.A., D.J.S., C.J., and K.L.; methodology, A.P.A., D.J.S., J.L.; validation, A.P.A., D.J.S., and K.L.; formal analysis, A.P.A., D.J.S., and J.L.; investigation, A.P.A., D.J.S., and J.L.; data curation, A.P.A., D.J.S., and J.L.; writing—original draft preparation, A.P.A.; writing—review and editing, A.P.A., D.J.S., C.J., and K.L.; visualization, A.P.A., D.J.S., and C.J.; supervision, D.J.S. and K.L.; project administration, D.J.S. and K.L.; funding acquisition, K.L. All authors have read and agreed to the published version of the manuscript.

Funding: The data used in this publication was made possible through support provided by the U.S. Agency for International Development, under the terms of Cooperative Agreement No. AID-OAA-A-12-00095. Additional support was provided by MIT D-Lab. Any opinions, findings, and conclusions expressed in this material are those of the authors and do not necessarily reflect the views of the U.S. Agency for International Development or MIT D-Lab.

Acknowledgments: This work relied heavily on many people who are taking on the challenging task of growing food on small farms and improving services for farmers. The authors would like to thank the farmers, agricultural extension agents, and researchers who graciously welcomed us to their farms, offices, and project sites. We would like to thank our colleagues in the MIT D-Lab network who assisted us with connections to the sector, refined our field research methods, and reviewed this article. Yashoda C. and Tusher C. provided support for our work in India, and Hubert Kimani and Lilian Lungo provided support in Kenya. We would also like to acknowledge Nicole Bridge, Katie Hauser, and Maggie Linak of USAID for their support. Finally, we would like to appreciate our project mentor, Dorn Cox. 
Conflicts of Interest: The authors declare no conflicts of interest.

\section{References}

1. BBC. The High-Tech Farming Revolution; BBC World News: London, UK, 2019.

2. FAO. How to Feed the World in 2050; FAO: Rome, Italy, 2009.

3. Gray, B.; Babcock, L.; Tobias, L.; McCord, M.; Herrera, A.; Cadavid, R. Digital Farmer Profiles: Reimagining Smallholder Agriculture; Grameen Foundation: Washington, DC, USA, 2018.

4. Ayaz, M.; Ammad-Uddin, M.; Sharif, Z.; Mansour, A.; Aggoune, E.-H.M. Internet-of-Things (IoT)-Based Smart Agriculture: Toward Making the Fields Talk. IEEE Access 2019, 7, 129551-129583. [CrossRef]

5. Liu, Y.; Langemeier, M.R.; Small, I.M.; Joseph, L.; Fry, W.E. Risk Management Strategies using Precision Agriculture Technology to Manage Potato Late Blight. Agron. J. 2017, 109, 562-575. [CrossRef]

6. Small, I.M.; Joseph, L.; Fry, W. Evaluation of the BlightPro Decision Support System for Management of Potato Late Blight Using Computer Simulation and Field Validation. Phytopathology 2015, 105, 1545-1554. [CrossRef] [PubMed]

7. Van Evert, F.K.; Gaitán-Cremaschi, D.; Gaitán-Cremaschi, D.; Kempenaar, C. Can Precision Agriculture Increase the Profitability and Sustainability of the Production of Potatoes and Olives? Sustainability 2017, 9, 1863. [CrossRef]

8. Saab, M.T.A.; Jomaa, I.; Skaf, S.; Fahed, S.; Todorović, M. Assessment of a Smartphone Application for Real-Time Irrigation Scheduling in Mediterranean Environments. Water 2019, 11, 252. [CrossRef]

9. Bragagnolo, J.; Amado, T.J.C.; Nicoloso, R.S.; Santi, A.L.; Fiorin, J.E.; Tabaldi, F. Optical crop sensor for variable-rate nitrogen fertilization in corn: II-Indices of fertilizer efficiency and corn yield. Rev. Bras. Ciênc. Solo 2013, 37, 1299-1309. [CrossRef]

10. Scharf, P.C. Crop Sensors for Managing Nitrogen; Foundation for Arable Research: Christchurch, New Zealand, 2009.

11. Fanzo, J. From big to small: The significance of smallholder farms in the global food system. Lancet Planet. Health 2017, 1, e15-e16. [CrossRef]

12. Maumbe, B.M.; Okello, J. Uses of Information and Communication Technology (ICT) in Agriculture and Rural Development in Sub-Saharan Africa. In Technology, Sustainability, and Rural Development in Africa; IGI Global: Hershey, PA, USA, 2013; pp. 113-134.

13. Garrity, J. Harnessing the Internet of Things for Global Development. SSRN Electron. J. 2015. [CrossRef]

14. Masinde, M. IoT applications that work for the African continent: Innovation or adoption? In Proceedings of the 2014 12th IEEE International Conference on Industrial Informatics (INDIN), Porto Alegre, Brazil, 27-30 July 2014; pp. 633-638.

15. Dlodlo, N.; Kalezhi, J.; Nomusa, D. The internet of things in agriculture for sustainable rural development. In Proceedings of the 2015 International Conference on Emerging Trends in Networks and Computer Communications (ETNCC), Windhoek, Namibia, 17-20 May 2015; pp. 13-18. [CrossRef]

16. Kshetri, N. The economics of the Internet of Things in the Global South. Third World Q. 2016, 38, 1-29. [CrossRef]

17. Munyua, H.; Adera, E.; Jensen, M. Emerging ICTs and their potential in revitalizing small scale agriculture in Africa. Agric. Inf. Worldw. 2009, 2, 3-9.

18. McEwen, A.; Cassimally, H. Designing the Internet of Things; Wiley: Hoboken, NJ, USA, 2013; ISBN 9781118430651.

19. Borgia, E. The Internet of Things vision: Key features, applications and open issues. Comput. Commun. 2014, 54, 1-31. [CrossRef]

20. U.S. Government. U.S. Government Global Food Security Strategy FY 2017-2021; U.S. Government: Washington, DC, USA, 2016.

21. Akuku, B.; Makini, F.; Wasilwa, L.; Kamau, G.; Makelo, M. Application of innovative ICT tools for linking Agricultural research knowledge and extension services to farmers in Kenya. In Proceedings of the 7th UbuntuNet Alliance Annual Conference, Lusaka, Zambia, 13-14 November 2014; pp. 13-20.

22. Krell, N.T.; Giroux, S.A.; Guido, Z.; Hannah, C.; Lopus, S.E.; Caylor, K.K.; Evans, T.P. Smallholder farmers' use of mobile phone services in central Kenya. Clim. Dev. 2020, 12, 1-13. [CrossRef] 
23. World Bank. World Bank Open Data. Available online: https://data.worldbank.org/indicator (accessed on 29 March 2019).

24. Newzoo. Global Mobile Market Report; Newzoo: San Francisco, CA, USA, 2019.

25. Antony, A.P.; Lu, J.; Sweeney, D.J. Seeds of Silicon: Internet of Things for Smallholder Agriculture; Massachusetts Institute of Technology: Cambridge, MA, USA, 2019; Available online: https://d-lab.mit.edu/resources/ publications/seeds-silicon-internet-things-smallholder-agriculture (accessed on 4 May 2020).

26. Bogue, R. Sensors key to advances in precision agriculture. Sens. Rev. 2017, 37, 1-6. [CrossRef]

27. Hsieh, H.-F.; Shannon, S.E. Three Approaches to Qualitative Content Analysis. Qual. Health Res. 2005, 15, 1277-1288. [CrossRef]

28. Jain, M.; Singh, B.; Srivastava, A.A.K.; Malik, R.K.; McDonald, A.J.; Lobell, D.B. Using satellite data to identify the causes of and potential solutions for yield gaps in India's Wheat Belt. Environ. Res. Lett. 2017, 12, 094011. [CrossRef]

29. Cecil, M.; Estes, L.D.; Evans, T.P.; Wolf, A. Using in situ Sensor Networks and Remotely Sensed Imagery to Improve Site-Specific Understanding of Maize Yield Variance. In AGU Fall Meeting; American Geophysical Union: San Francisco, CA, USA, 2019.

30. Dean, T.J.; Bell, J.P.; Baty, A.J.B. Soil moisture measurement by an improved capacitance technique, Part I. Sensor design and performance. J. Hydrol. 1987, 93, 67-78. [CrossRef]

31. IDEO.org. The Magic Stick. Available online: https://www.ideo.org/perspective/the-magic-stick (accessed on 17 August 2018).

32. Gardner, C.; Dean, T.; Cooper, J. Soil Water Content Measurement with a High-Frequency Capacitance Sensor. J. Agric. Eng. Res. 1998, 71, 395-403. [CrossRef]

33. Eller, H.; Denoth, A. A capacitive soil moisture sensor. J. Hydrol. 1996, 185, 137-146. [CrossRef]

34. Makario, J.; Ngetich, K.; Maina, C. Long Range Low Power Sensor Networks for Agricultural Monitoring-A Case Study in Kenya. In Proceedings of the 2019 IST-Africa Week Conference (IST-Africa), Nairobi, Kenya, 8-10 May 2019; pp. 1-8.

35. Payero, J.O.; Qiao, X.; Khalilian, A.; Mirzakhani-Nafchi, A.; Davis, R. Evaluating the Effect of Soil Texture on the Response of Three Types of Sensors Used to Monitor Soil Water Status. J. Water Resour. Prot. 2017, 9, 566-577. [CrossRef]

36. Yamazoe, N.; Shimizu, Y. Humidity sensors: Principles and applications. Sens. Actuators 1986, 10, 379-398. [CrossRef]

37. Bi, H.; Yin, K.; Xie, X.; Ji, J.; Wan, S.; Sun, L.-T.; Terrones, M.; Dresselhaus, M.S. Ultrahigh humidity sensitivity of graphene oxide. Sci. Rep. 2013, 3, 1-7. [CrossRef] [PubMed]

38. Larson, G.F. Electrical Sensor for Measuring Moisture in Landscape and Agricultural Soils. U.S. Patent 4531087, 23 June 1985.

39. Mulenga, R.; Kalezhi, J.; Musonda, S.K.; Silavwe, S. Applying Internet of Things in Monitoring and Control of an Irrigation System for Sustainable Agriculture for Small-Scale Farmers in Rural Communities. In Proceedings of the 2018 IEEE PES/IAS PowerAfrica, Cape Town, South Africa, 28-29 June 2018; pp. 1-9.

40. Meyer, T.C.; Hancke, G.P. Design of a smart sprinkler system. In Proceedings of the TENCON 2015-2015 IEEE Region 10 Conference, Macao, China, 1-4 November 2015; Volume 2016, pp. 1-6.

41. Bogena, H.; Huisman, J.A.; Oberdörster, C.; Vereecken, H. Evaluation of a low-cost soil water content sensor for wireless network applications. J. Hydrol. 2007, 344, 32-42. [CrossRef]

42. Staggenborg, S.A.; Carignano, M.; Haag, L. Predicting Soil pH and Buffer pH In Situ with a Real-Time Sensor. Agron. J. 2007, 99, 854-861. [CrossRef]

43. IDEO.org. Spoilage Sensor. Available online: https://www.ideo.org/perspective/spoilage-sensor (accessed on 17 August 2018).

44. Wild, K.; Auernhammer, H. A weighing system for local yield monitoring of forage crops in round balers. Comput. Electron. Agric. 1999, 23, 119-132. [CrossRef]

45. Potapovs, A.; Avotins, A.; Apse-Apsitis, P.; Gorobetz, M.; Ceirs, P. Continuous Crop Weight Measurement Sensor Calibration Algorithm for Industrial Greenhouse. In Proceedings of the 2018 IEEE 59th International Scientific Conference on Power and Electrical Engineering of Riga Technical University (RTUCON), Riga, Latvia, 12-13 November 2018; pp. 1-6.

46. Jagtap, S.; Bhatt, C.; Thik, J.; Rahimifard, S. Thik Monitoring Potato Waste in Food Manufacturing Using Image Processing and Internet of Things Approach. Sustainability 2019, 11, 3173. [CrossRef] 
47. Janssen, S.; Schmitt, K.; Blanke, M.; Bauersfeld, M.L.; Wöllenstein, J.; Lang, W. Ethylene detection in fruit supply chains. Philos. Trans. R. Soc. A Math. Phys. Eng. Sci. 2014, 372, 20130311. [CrossRef]

48. Chaudhary, D.; Nayse, S.; Waghmare, L. Application of Wireless Sensor Networks for Greenhouse Parameter Control in Precision Agriculture. Int. J. Wirel. Mob. Networks 2011, 3, 140-149. [CrossRef]

49. Ahonen, T.; Virrankoski, R.; Elmusrati, M. Greenhouse Monitoring with Wireless Sensor Network. In Proceedings of the 2008 IEEE/ASME International Conference on Mechtronic and Embedded Systems and Applications, Beijing, China, 12-15 October 2008; pp. 403-408.

50. Murphy, F.E.; Popovici, E.; Whelan, P.; Magno, M. Development of an heterogeneous wireless sensor network for instrumentation and analysis of beehives. In Proceedings of the 2015 IEEE International Instrumentation and Measurement Technology Conference (I2MTC) Proceedings, Pisa, Italy, 11-14 May 2015; Volume 2015, pp. 346-351.

51. Tilly, N.; Hoffmeister, D.; Cao, Q.; Huang, S.; Lenz-Wiedemann, V.; Miao, Y.; Bareth, G. Multitemporal crop surface models: Accurate plant height measurement and biomass estimation with terrestrial laser scanning in paddy rice. J. Appl. Remote. Sens. 2014, 8, 83671. [CrossRef]

52. Friedli, M.; Kirchgessner, N.; Grieder, C.; Liebisch, F.; Mannale, M.; Walter, A. Terrestrial 3D laser scanning to track the increase in canopy height of both monocot and dicot crop species under field conditions. Plant Methods 2016, 12, 9. [CrossRef]

53. Sun, H.; Zhu, Q.; Ren, J.; Barclay, D.; Thomson, W. Combining Image Analysis and Smart Data Mining for Precision Agriculture in Livestock Farming. In Proceedings of the 2017 IEEE International Conference on Internet of Things (iThings) and IEEE Green Computing and Communications (GreenCom) and IEEE Cyber, Physical and Social Computing (CPSCom) and IEEE Smart Data (SmartData), Exeter, UK, 21-23 June 2017; Volume 2018, pp. 1065-1069.

54. Saeys, W.; Lenaerts, B.; Craessaerts, G.; De Baerdemaeker, J. Estimation of the crop density of small grains using LiDAR sensors. Biosyst. Eng. 2009, 102, 22-30. [CrossRef]

55. Weiss, U.; Biber, P. Plant detection and mapping for agricultural robots using a 3D LIDAR sensor. Robot. Auton. Syst. 2011, 59, 265-273. [CrossRef]

56. Filippa, G.; Cremonese, E.; Migliavacca, M.; Galvagno, M.; Sonnentag, O.; Humphreys, E.R.; Hufkens, K.; Ryu, Y.; Verfaillie, J.; Di Cella, U.M.; et al. NDVI derived from near-infrared-enabled digital cameras: Applicability across different plant functional types. Agric. For. Meteorol. 2018, 249, 275-285. [CrossRef]

57. Nie, P.; Dong, T.; He, Y.; Qu, F. Detection of Soil Nitrogen Using Near Infrared Sensors Based on Soil Pretreatment and Algorithms. Sensors 2017, 17, 1102. [CrossRef] [PubMed]

58. Piikki, K.; Söderström, M.; Eriksson, J.; John, J.M.; Muthee, P.I.; Wetterlind, J.; Lund, E. Performance Evaluation of Proximal Sensors for Soil Assessment in Smallholder Farms in Embu County, Kenya. Sensors 2016, 16, 1950. [CrossRef] [PubMed]

59. Shepherd, K.; Walsh, M.G.; Walsh, M. Infrared Spectroscopy_Enabling an Evidence-Based Diagnostic Surveillance Approach to Agricultural and Environmental Management in Developing Countries. J. Near Infrared Spectrosc. 2007, 15, 1-19. [CrossRef]

60. Colaço, A.F.; Bramley, R.G.V. Do crop sensors promote improved nitrogen management in grain crops? Field Crop Res. 2018, 218, 126-140. [CrossRef]

61. Habte, A.; Sengupta, M.; Andreas, A.; Narasappa, R.; Thomas, T.; Wolf, A.; Gueymard, C.A. Characterization of a Low-Cost Multi-Parameter Sensor for Solar Resource Applications. In Proceedings of the 2018 IEEE 7th World Conference on Photovoltaic Energy Conversion (WCPEC) (A Joint Conference of 45th IEEE PVSC, 28th PVSEC \& 34th EU PVSEC), Waikoloa Village, HI, USA, 10-15 June 2018; pp. 2309-2312.

62. Mwebaze, E.; Owomugisha, G. Machine Learning for Plant Disease Incidence and Severity Measurements from Leaf Images. In Proceedings of the 2016 15th IEEE International Conference on Machine Learning and Applications (ICMLA), Anaheim, CA, USA, 18-20 December 2016; pp. 158-163.

63. Bbosa, D.; Brumm, T.J.; Bern, C.J.; Rosentrater, K.A.; Raman, D.R. Evaluation of Hermetic Maize Storage in 208 Liter (55 Gal) Steel Barrels for Smallholder Farmers. Trans. ASABE 2017, 60, 981-987. [CrossRef]

64. Park, D.H.; Kang, B.-J.; Cho, K.-R.; Shin, C.; Cho, S.-E.; Park, J.W.; Yang, W.-M. A Study on Greenhouse Automatic Control System Based on Wireless Sensor Network. Wirel. Pers. Commun. 2009, 56, 117-130. [CrossRef]

65. Ham, J.M.; Senock, R.S. On the Measurement of Soil Surface Temperature. Soil Sci. Soc. Am. J. 1992, 56, 370-377. [CrossRef] 
66. Weddi, J.D. SciDev.Net. September 2019. Available online: https://www.scidev.net/sub-saharan-africa/ fisheries/feature/using-internet-technology-to-improve-cage-fish-farming.html\# (accessed on 18 April 2019).

67. Michalski, A. Flow measurements in open irrigation channels. IEEE Instrum. Meas. Mag. 2000, 3, 12-16. [CrossRef]

68. Nagel, C.; Beach, J.; Iribagiza, C.; Thomas, E.A. Evaluating Cellular Instrumentation on Rural Handpumps to Improve Service Delivery-A Longitudinal Study in Rural Rwanda. Environ. Sci. Technol. 2015, 49, 14292-14300. [CrossRef] [PubMed]

69. Blumstein, D.T.; Mennill, D.J.; Clemins, P.; Girod, L.; Yao, K.; Patricelli, G.; Deppe, J.L.; Krakauer, A.; Clark, C.; Cortopassi, K.A.; et al. Acoustic monitoring in terrestrial environments using microphone arrays: Applications, technological considerations and prospectus. J. Appl. Ecol. 2011, 48, 758-767. [CrossRef]

70. Maina, C.; Muchiri, D.; Njoroge, P. Cost Effective Acoustic Monitoring of Biodiversity and Bird Populations in Kenya; bioRxiv: Cold Spring Harbor, NY, USA, 2016.

71. Amusa, K.A.; Opeodu, F.A.; Adewusi, A.; Adewunmi, T.O. A SONAR-Based Water Level Monitoring System: An Experimental Design. FUOYE J. Eng. Technol. 2018, 3, 21-24.

72. Maina, C. IoT at the grassroots-Exploring the use of sensors for livestock monitoring. In Proceedings of the 2017 IST-Africa Week Conference (IST-Africa), Windhoek, Namibia, 30 May-2 June 2017; pp. 1-8.

73. Halachmi, I.; Guarino, M.; Bewley, J.; Pastell, M. Smart Animal Agriculture: Application of Real-Time Sensors to Improve Animal Well-Being and Production. Annu. Rev. Anim. Biosci. 2019, 7, 403-425. [CrossRef] [PubMed]

74. Workman, R. Measuring Road Condi/on of the First Mile. Atdf J. 2019, 9, 18-27.

75. Thomas, E.A.; Needoba, J.; Kaberia, D.; Butterworth, J.; Adams, E.C.; Oduor, P.; Macharia, D.; Mitheu, F.; Mugo, R.; Nagel, C. Quantifying increased groundwater demand from prolonged drought in the East African Rift Valley. Sci. Total. Environ. 2019, 666, 1265-1272. [CrossRef]

76. Métras, S.R.; Magalhaes, R.J.S.; Dinh, Q.H.; Fournié, G.; Gilbert, J.; Huu, D.; Roland-Holst, D.; Otte, J.; Pfeiffer, D.U. An assessment of the feasibility of a poultry tracing scheme for smallholders in Vietnam. Rev. Sci. Tech. de l'OIE 2011, 30, 703-714. [CrossRef]

77. Kubasu, L.N.; Wachira, H. Tackling cattle rustling menace using RFID/GPS livestock traceability applications in North Rift Kenya: Assessment of the options and way forward. In Proceedings of the IST Africa, Durban, South Africa, 19-21 May 2010; pp. 1-8.

78. Mutembesa, D.; Mwebaze, E.; Nsumba, S.; Omongo, C.; Mutaasa, H. Mobile Community Sensing with Smallholder Farmers in a Developing Nation; a Scaled Pilot for Crop Health Monitoring. arXiv 2019, arXiv:1908.07047. Available online: https://arxiv.org/abs/1908.07047 (accessed on 10 April 2019).

79. Zheleva, M.; Bogdanov, P.; Zois, D.-S.; Xiong, W.; Chandra, R.; Kimball, M. Smallholder Agriculture in the Information Age. In Proceedings of the 2017 Workshop on Recognizing Families In the Wild-RFIW '17; Association for Computing Machinery (ACM), Santa Barbara, CA, USA, 27 october 2017; pp. 59-70.

80. Neményi, M.; Mesterházi, P.; Pecze, Z.; Stépán, Z. The role of GIS and GPS in precision farming. Comput. Electron. Agric. 2003, 40, 45-55. [CrossRef]

81. Ferrández-Pastor, F.-J.; García-Chamizo, J.M.; Nieto-Hidalgo, M.; Mora-Martínez, J. Precision Agriculture Design Method Using a Distributed Computing Architecture on Internet of Things Context. Sensors 2018, 18, 1731. [CrossRef]

82. Mekki, K.; Bajic, E.; Chaxel, F.; Meyer, F. A comparative study of LPWAN technologies for large-scale IoT deployment. ICT Express 2019, 5, 1-7. [CrossRef]

83. Raymond, J. The Internet of Things: A Study in Hype, Reality, Disruption and Growth; US Research: Bethesda, MD, USA, 2014.

84. Daum, T.; Villalba, R.; Anidi, O.; Mayienga, S.M.; Gupta, S.; Birner, R. Uber for Tractors? Opportunities and Challenges of Digital Tools for Tractor Hire in India and Nigeria. SSRN Electron. J. 2020. [CrossRef]

85. Pandey, B.; Foster, R.; Holthaus, J.; Shrestha, B.; Ngetich, B.; Kunen, E.; Romero, M.; Seo, T.; Renné, D. Solar Water Pumping: Kenya and Nepal Market Acceleration. In Proceedings of the ISES Solar World Congress 2015, Daegu, Korea, 8-12 November 2015; pp. 1-12. [CrossRef]

86. Dorigo, W.; Wagner, W.; Hohensinn, R.; Hahn, S.; Paulik, C.; Xaver, A.; Gruber, A.; Drusch, M.; Mecklenburg, S.; Van Oevelen, P.; et al. The International Soil Moisture Network: A data hosting facility for global in situ soil moisture measurements. Hydrol. Earth Syst. Sci. 2011, 15, 1675-1698. [CrossRef] 
87. Turman-Bryant, N.; Nagel, C.L.; Stover, L.; Muragijimana, C.; Thomas, E.A. Improved Drought Resilience Through Continuous Water Service Monitoring and Specialized Institutions-A Longitudinal Analysis of Water Service Delivery Across Motorized Boreholes in Northern Kenya. Sustainability 2019, 11, 3046. [CrossRef]

88. Wilson, D.; Coyle, J.R.; Thomas, E.A. Ensemble machine learning and forecasting can achieve $99 \%$ uptime for rural handpumps. PLoS ONE 2017, 12, e0188808. [CrossRef] [PubMed]

89. Maina, C.; Smith, M.; Mwebaze, E.; Mubangizi, M.; Quinn, J.A.; Neil, D. Data Science Africa-An Initiative to Bridge the Data Science Skills Gap in Africa. In Proceedings of the SciDataCon, Denver, CO, USA, 12-13 September 2016; pp. 1-4.

90. Pongnumkul, S.; Chaovalit, P.; Surasvadi, N. Applications of Smartphone-Based Sensors in Agriculture: A Systematic Review of Research. J. Sens. 2015, 2015, 1-18. [CrossRef]

(C) 2020 by the authors. Licensee MDPI, Basel, Switzerland. This article is an open access article distributed under the terms and conditions of the Creative Commons Attribution (CC BY) license (http://creativecommons.org/licenses/by/4.0/). 